\title{
Masimo SpHb: is it reliable?
}

Pedrosa, F.; Luís, M.; Galveias, I.; Conde, P., Alves, A.; Hospital de Santa Maria, Lisbon, Portugal

\section{Background:}

Non-invasive methods of monitoring hemodynamics are becoming a more and more frequent choice intraoperatively. Their accuracy, comparing with gold-standard measurements, is the downside of these new methods. No previous studies were performed in this matter.

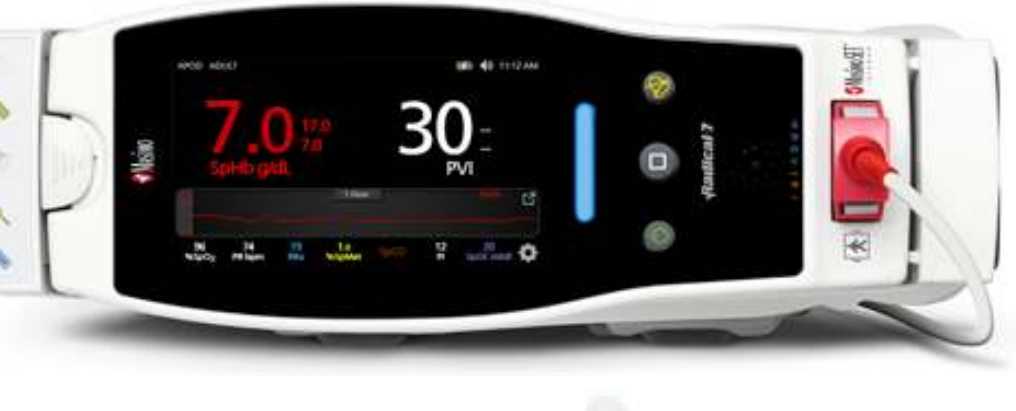

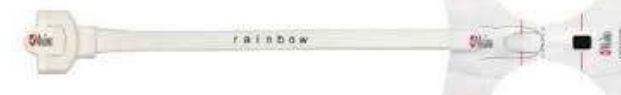

Masimo rainbow ${ }^{\circledR}$ is a continuous method that through plethysmography curve analysis, monitors not only a estimated value for pulse pressure variation but also estimates blood hemoglobin $(\mathrm{SpHb})$ and hemoglobin saturation.

\section{Goal of study:}

Prospective, observacional study, that aims to find a correlation between $\mathrm{SpHb}$ variation with the one from gas blood analysis $(\mathrm{GHb})$, our standard method.

\section{Materials and Methods:}

$\leftarrow$ Patients submitted to an elective vascular procedure under general anesthesia during October 2016.

- Each patient was monitored on the same arm with a finger sensor of Masimo rainbow and an arterial catheter inserted.

- The values of $\mathrm{SpHb}$ and $\mathrm{GHb}$ were registered at the beginning and every hour during the surgical procedure.

\section{Discussion and Results:}

19

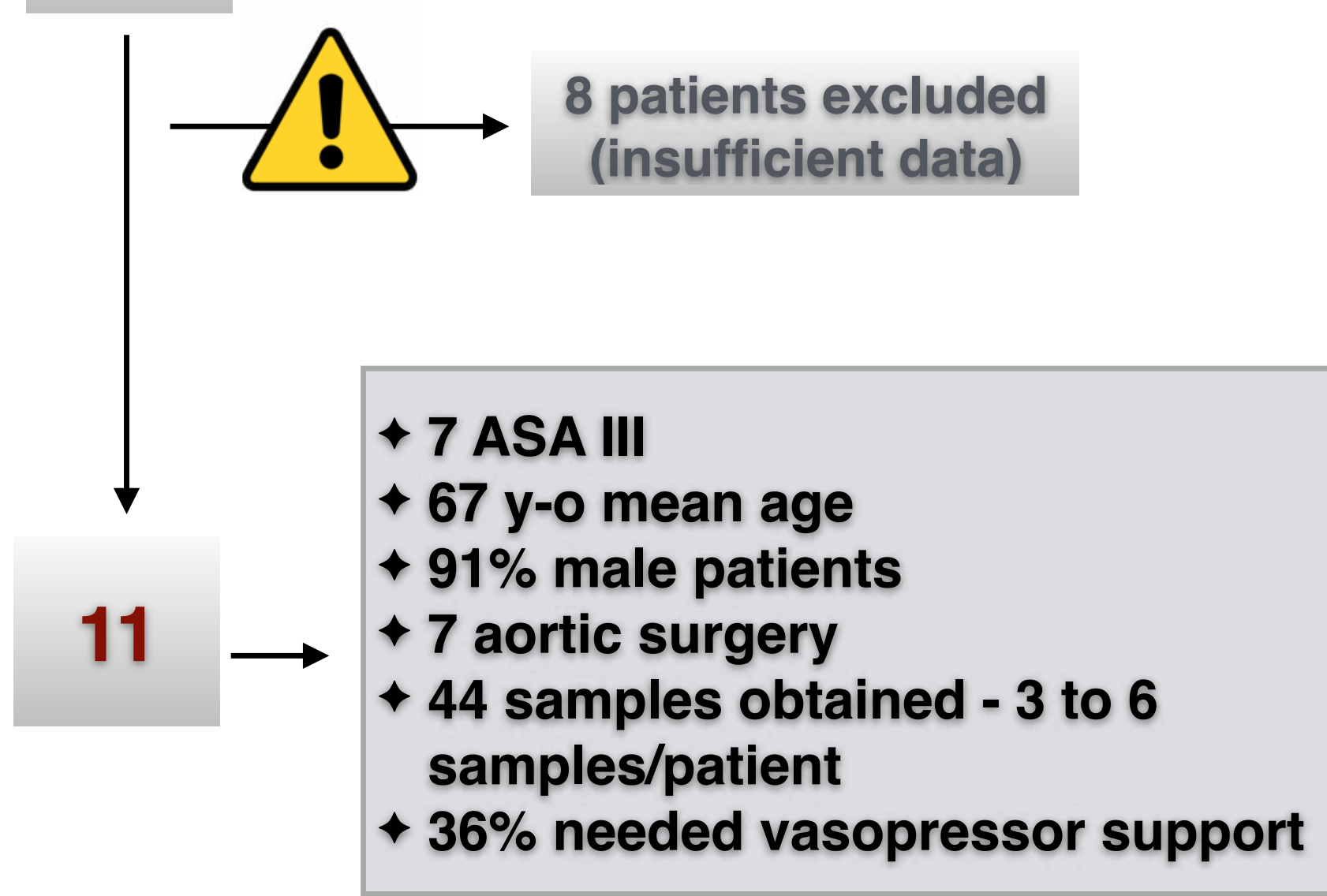

Linear regression and range of determination coefficient were performed to correlate the trend of $\mathrm{SpHb}$ with $\mathrm{GHb}$.

Global correlation between $\mathrm{SpHb}$ and $\mathrm{GHb}(\mathrm{n}=11)$

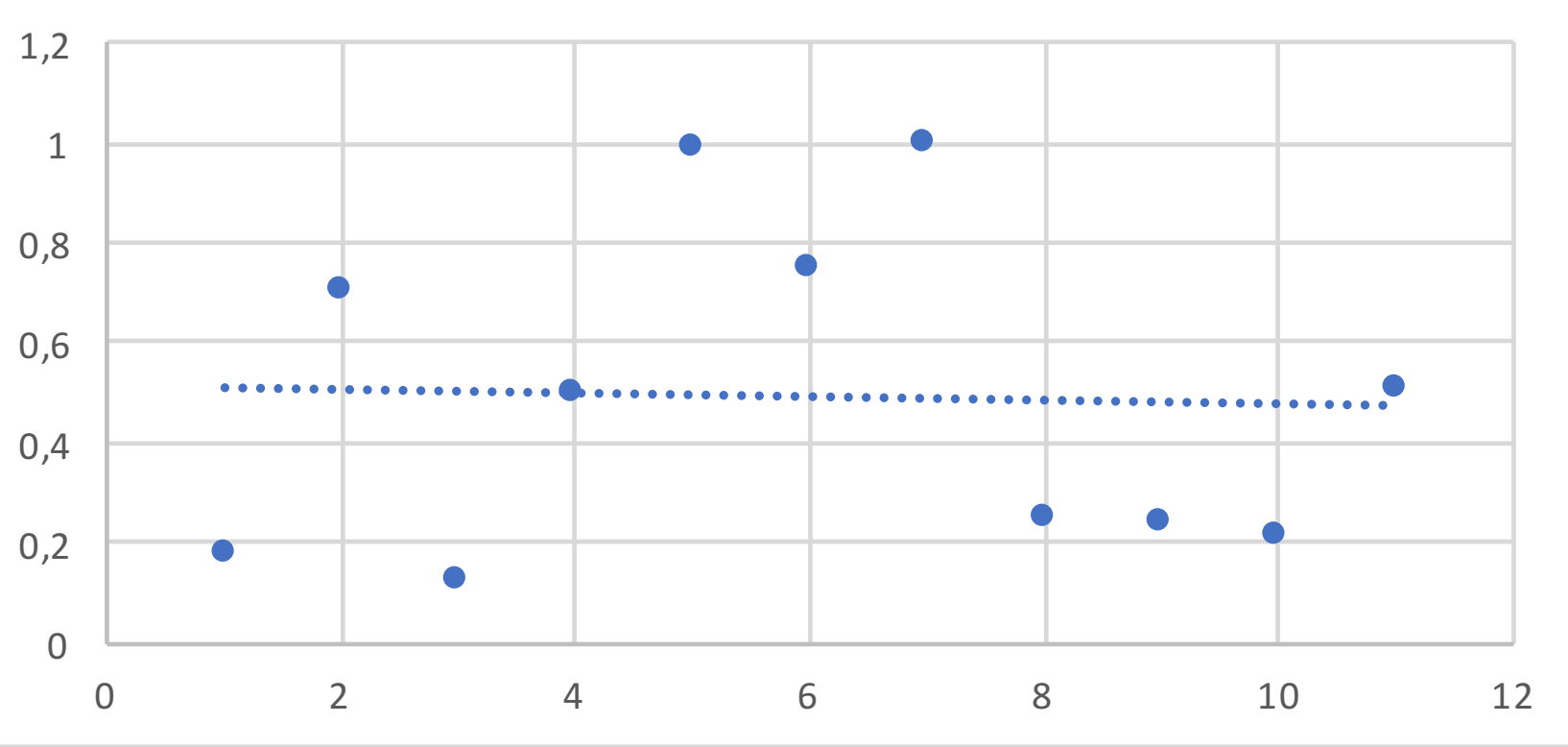

$\mathrm{R}^{2}$ ranged between 0,12 to 1 .

The median value was 0,49

Conclusion:

$+\mathrm{SpHb}$ variation does not correlate with standard method trending analysis.

+ Its unreliability might compromise decision-making in adverse intra-operative setting, based alone on $\mathrm{SpHb}$ interpretation.

+ Limitations of this study: small sample size and impossibility to attenuate all the confounding factors to Masimo readings, above all the great prevalence of peripheral arterial disease in this group. 